\title{
AVALIAÇÃO DA SATISFAÇÃO DE ALUNOS DE FRANQUIAS DE ENSINO
}

\author{
SATISFACTION EVALUATION OF STUDENTS FROM EDUCATION FRANCHISES
}

\author{
Harrison Bachion Ceribeli \\ Universidade de São Paulo - USP
}

Edgard Monforte Merlo

Universidade de São Paulo - USP

José Prado Villela dos Reis

Universidade de São Paulo - USP

\section{RESUMO}

Recentemente, o segmento de ensino de idiomas cresceu muito no Brasil, crescendo também o número de redes de franquias atuantes no setor, tornando-o altamente competitivo. Assim, este trabalho teve como objetivo avaliar a satisfação de clientes de uma franquia de ensino de idiomas e, posteriormente, identificar quais os fatores que influenciam de maneira mais significativa nesta satisfação. Foi desenvolvido um questionário com base no modelo servqual ampliado por questões de imagem e marca, aplicado em uma amostra composta por 177 alunos de quatro escolas de idiomas de Ribeirão Preto. Como conclusão, percebeu-se que os alunos mostraram-se satisfeitos com o curso de línguas fornecido pela rede estudada; entretanto, alguns itens fundamentais para a total satisfação destes consumidores não estavam sendo atendidos de maneira adequada, principalmente em relação a questões tangíveis. Além disso, este trabalho discute a importância da comunicação entre franqueados e franqueadores, de modo a garantir a satisfação dos clientes.

Palavras-chave: Satisfação. Franquias. Escola de idiomas.

\section{ABSTRACT}

Recently, the segment of language teaching has grown in Brazil, also increasing the number of networks of franchises operating in the sector, making it highly competitive. Thus, this study aimed to evaluate the satisfaction of customers from education francises and then identify the factors that influence more significantly in satisfaction. A questionnaire was developed based on SERVQUAL model extended by questions of image and brand, and applied to a sample of 177 students from four language schools in Ribeirão Preto. In conclusion, it was noticed that students were satisfied with the language training provided by the network studied, however, a few key items for the total satisfaction of consumers were not being addressed adequately, especially in relation to tangible issues. In addition, this paper discusses the importance of communication between franchisees and franchisors, to ensure customer satisfaction.

Keywords: Satisfaction. Franchising. Language school. 


\section{INTRODUÇÃO}

A partir dos anos 80 e 90, no Brasil, com a abertura dos mercados, ocorreram grandes mudanças sociais, culturais, políticas, econômicas e tecnológicas. 0 processo de internacionalização da economia acabou com as barreiras geográficas, universalizou o comércio de bens e serviços, possibilitou a formação de blocos econômicos e culminou em uma agilidade de comunicação nunca antes experimentada, alterando definitivamente os padrões de comportamento em todas as áreas de negócios e de conhecimento.

Para atender às novas exigências que surgiram com estas mudanças referentes à globalização, os profissionais que atuam no mercado passaram a buscar constantemente novas competências e conhecimentos. E, acompanhando estas tendências de aprimoramento contínuo por parte dos profissionais e de internacionalização por parte das empresas, cresceram as opções de escolas de idiomas, que oferecem cursos de ensino e aprimoramento em línguas estrangeiras.

Além disso, outra tendência que merece destaque neste cenário é o crescente número de redes de franquias, que passaram a atuar em diversos setores na economia moderna, incluindo o setor de educação.

Deve-se destacar, portanto, a concorrência no segmento de escolas de idiomas, que se tornou muito acirrada nos últimos anos, já que o crescimento deste setor passou a atrair inúmeras redes de franquias, sendo que esta concorrência é ainda mais agressiva na cidade de Ribeirão Preto, que abriga um grande número de estudantes, pela presença de inúmeras universidades na cidade.

Sendo assim, conforme afirma Kotler (2000), deve-se buscar cada vez mais identificar e atender às expectativas dos clientes de maneira a gerar maior satisfação, evitando, deste modo, que a concorrência cresça e que seus clientes procurem outras empresas para atender a suas demandas.

Levando em consideração este contexto, foi desenvolvido este estudo, cujo objetivo é avaliar a satisfação de clientes de franquias de ensino e, posteriormente, identificar quais os fatores que influenciam de maneira mais significativa nesta satisfação.

Para tanto, foram levantados os principais conceitos sobre franquias e comportamento do consumidor e, posteriormente, foi desenvolvido um questionário com base no modelo servqual ampliado, que foi então aplicado junto a alunos de quatro escolas de Ribeirão Preto que fazem parte de uma mesma rede de franquias de ensino de idiomas. Os resultados da pesquisa foram tabulados e posteriormente foram aplicadas diferentes técnicas estatísticas, dentre elas estatísticas descritivas e análise de regressão, de modo a possibilitar que os objetivos deste trabalho fossem alcançados.

Deve-se ressaltar que a relevância deste trabalho está no fato de que a satisfação do consumidor deve ser uma preocupação constante de qualquer empresa, especialmente as prestadoras de serviços, que têm maior contato com os clientes, já que estes podem se afastar caso os serviços prestados não atendam às expectativas formadas, o que contribui para o enfraquecimento da marca. E é devido à importância crescente que a satisfação dos consumidores passou a ocupar no cotidiano das empresas que os autores optaram por desenvolver um trabalho voltado a esta área, de modo a propor um modelo de avaliação da satisfação de clientes que pode ser facilmente utilizado por redes de franquias de ensino, 
segmento este que passa por relevante expansão no Brasil.

\section{REFERENCIAL TEÓRICO}

\section{SISTEMA DE FRANQUIAS}

Franquias, segundo Parente (2000), é um sistema no qual um franqueador cede o direito de uso de uma marca e de procedimentos específicos para determinados franqueados, de modo que estes possam conduzir um negócio padronizado, pagando pelo direito de utilizar esta marca e respectivos procedimentos operacionais relacionados.

Já Kotler (2000, p. 543) explica que o sistema de franquias pode ser entendido como uma "associação contratual entre um franqueador (fabricante, atacadista, organização de serviços) e franqueados (empresários independentes que compram o direito de possuir e operar uma ou mais unidades no sistema de franquias)". Além disso, este autor ressalta que o uso de franquias, também conhecido como franchising, tem sido cada vez mais utilizado como estratégia de expansão dos negócios.

No sistema de franquias, o franqueador, normalmente um fabricante, um atacadista, ou uma companhia de serviços, concede a uma pequena empresa ou indivíduo (o franqueado) o direito de conduzir um negócio utilizando determinados procedimentos previamente delimitados por um período específico de tempo (MORGENSTEIN; STRONGIN, 1992).

Por meio da utilização de franquias, as empresas procuram combinar as vantagens do negócio gerenciado pelo proprietário com a eficiência da centralização da tomada de decisões, característica da operação de cadeia de lojas: os franqueados são motivados a ter êxito em sua própria loja, para auferir lucro, enquanto que os franqueadores são motivados a criar novos produtos e sistemas e a promover a marca, pois são remunerados a partir de royalties, calculados sobre o valor das vendas (LEVY; WEITZ, 200).

Conforme afirma Mauro (1999), o uso de franchising como estratégia de distribuição faz parte da tendência mundial de uma maior integração entre os membros do canal de distribuição. Além disso, este autor ressalta que esta integração tem como intuito maximizar os resultados globais do sistema, aumentando a competitividade dos canais, já que a competição não ocorre mais apenas entre empresas isoladas, mas entre sistemas integrados de marketing (KOTLER, 2000).

De acordo com Levy e Weitz (2000), embora não haja estatísticas precisas disponíveis, estima-se que a taxa de sucesso para abertura de novos negócios é de cerca de $20 \%$, ou seja, a cada cinco novas empresas abertas, apenas uma sobrevive. Ao comprar uma empresa já existente, este índice sobe para 70\%, e, ao adquirir uma franquia, a taxa de sucesso sobe para 90\%. Segundo Mauro (1999), no mercado brasileiro, ao somar unidades fechadas e unidades que mudaram de proprietários, o índice de insucessos no setor de franquias gira em torno de $10 \%$, o que confirma as estimativas de Levy e Weitz (2000).

Mauro (1999) afirma que o sistema de franquias do modo como é conhecido atualmente só foi desenvolvido no meio do século XIX, quando a Singer Sewing Machine Company franqueou a comerciantes independentes sua marca e produtos, para ampliar sua participação de mercado. Da mesma maneira, em 1989, a General Motors adotou o mesmo sistema para expandir sua rede de distribuição, e, em 1899, foi a Coca-Cola quem começou a outorgar licenças no sistema de franquias para indústrias de engarrafamento de refrigerantes. Outros exemplos citados por Mauro (1999) são a Hertz Rent-a-car, empresa que atua no ramo de 
aluguel de automóveis, em 1921, e, a partir dos anos 30, algumas companhias de petróleo que franquearam seus postos de gasolina, antes operados diretamente.

Como vantagens do sistema de franquias, do ponto de vista do franqueado, pode-se citar o fato de ser um método de negócios já testado e comprovado; a disponibilidade de manuais operacionais e de treinamento; o nome e a marca, que já são conhecidos no mercado; e a centralização das compras, que, além de transferirem para o franqueador parte do processo de negociação com fornecedores, ainda favorece o desenvolvimento de economias de escala. Já como desvantagens, também do ponto de vista do franqueado, pode-se citar o pagamento de taxas e royalties; a existência de regras e procedimentos rígidos; as restrições para o cancelamento do contrato ou venda do negócio; a dependência significativa em relação ao franqueador; e a existência de conflitos franqueado - franqueador (LEVY, WEITZ, 2000).

Já do ponto de vista do franqueador, as vantagens do sistema de franquias são rapidez da expansão; melhor imagem; economias de escala; descentralização da gestão; e motivação maior por parte dos franqueados; além da maior participação de mercado e ampla cobertura geográfica. E, como desvantagens para o franqueador, pode-se citar perda parcial de controle; maiores custos de formatação e supervisão; perda de sigilo de informações e know how; autonomia parcial para o desenvolvimento de produtos e alterações na marca; além do risco de perda da padronização (DAHAD et al., 1996).

Foster (1995) destaca que um sistema moderno de franquias deve ter quatro componentes básicos: (1) uma identidade, geralmente baseada no desenvolvimento de uma marca registrada; (2) um sistema operacional ou um formato de negócio, incluindo especificações operacionais e padrões de qualidade de produtos e serviços; (3) um sistema de apoio, geralmente composto de treinamento e assistência contínua em marketing, compras e aspectos operacionais do negócio; e (4) um relacionamento financeiro estável, baseado no estabelecimento de uma taxa única e royalties permanentes baseados em um determinado percentual do faturamento bruto.

Finalmente, de acordo com Mauro (1999), em um sistema de franquias, a relação entre franqueador e franqueados não deve ser baseada apenas em regras estipuladas por contratos e manuais, mas também no desenvolvimento de confiança mútua e objetivos comuns. 0 franqueador deve atuar em conjunto com os franqueados para a obtenção do melhor desempenho de cada unidade, e do sistema como um todo, e o franqueado, por sua vez, deve estar atento às tendências, suprindo o franqueador de informações que possibilitem a melhoria dos resultados globais da rede.

\section{SISTEMA DE FRANQUIAS NO BRASIL}

Segundo dados coletados frente à Associação Brasileira de Franchising (ABF) em 2009, tanto o faturamento, quanto o número de redes e de franquias abertas encontram-se em plena expansão, e a tendência é de que este crescimento mantenha-se nos próximos anos. A figura 1 ilustra esta afirmação, indicando a evolução do faturamento neste setor. 0 número de redes que utilizam o sistema de franquias no Brasil saltou de 600, em 2001, para 1.197, em 2007, e 1.379, em 2008, representando um crescimento de 129,83\% entre 2001 e 2008 . Além disso, deve-se destacar que, entre 2007 e 2008, o número de redes subiu cerca de 15,2\%, o que reforça a afirmação de que o sistema de franquias está em plena expansão no mercado brasileiro.

Outro dado relevante disponibilizado pela $\mathrm{ABF}$ está relacionado ao número de lojas 
franqueadas abertas, que subiu de 51.000, em 2001, para 71.954, em 2008, o que representa um crescimento de aproximadamente $41 \%$. Este dado indica que os empresários também estão considerando o sistema de franquias para abertura de novos negócios como um caminho de sucesso.

Ainda segundo a Associação Brasileira de Franchising (2009), as redes de franquias presentes no Brasil atuam nos seguintes segmentos: (1) acessórios pessoais e calçados; (2) alimentação; (3) educação e treinamento; (4) esporte, saúde, beleza e lazer; (5) fotos, gráficas e sinalização; (6) hotelaria e turismo; (7) informática e eletrônicos; (8) limpeza e conservação; (9) móveis, presentes, decoração e mobiliárias; (10) negócios, serviços e outros varejos; (11) veículos; e (12) vestuário.

Figura 1: Faturamento do setor de franchising

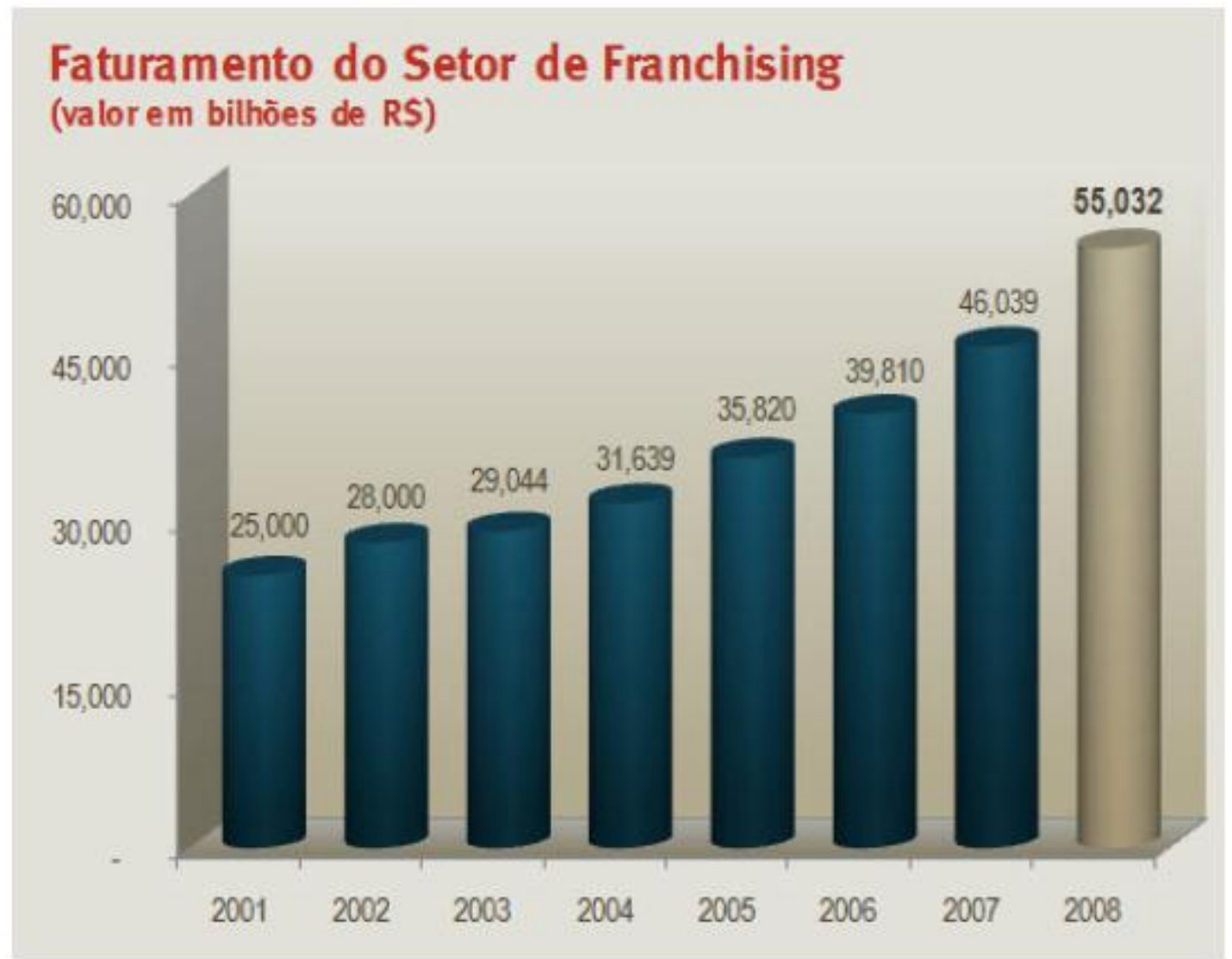

Fonte: Associação Brasileira de Franchising, 2009

E, dentre estes segmentos, os que apresentaram maior crescimento segundo o critério de faturamento, de 2007 para 2008, foram os segmentos de acessórios pessoais e calçados, veículos e vestuário, com crescimento no faturamento de, respectivamente, 44,8\%, 31,7\% e $27,2 \%$.

Já as redes que mais cresceram, em número de novas unidades abertas entre 2007 e 2008, foram as redes de franquias que atuam nos ramos de acessórios pessoais e calçados, vestuário e alimentação, alcançando crescimento do número de novas lojas abertas de, respectivamente, $33,3 \%, 27,2 \%$ e $22,6 \%$.

Cabe destacar, porém, que alguns setores sofreram pequena retração entre 2007 e 2008, tanto em faturamento (franquias de limpeza e conservação, com queda no faturamento de 
1,4\%), quanto no número de lojas abertas (franquias de fotos, gráficas e sinalização, limpeza e conservação, e veículos, com quedas de, respectivamente $0,7 \%, 2,2 \%$ e $4,1 \%$ ).

Entretanto, deve-se ressaltar que, apesar de alguns segmentos de franquias apresentarem uma leve retração, a tendência para o sistema de franquias é de expansão, já que este sistema tem mostrado grande taxa de sucesso na abertura de novas empresas (ABF, 2009).

\section{SATISFAÇÃO DO CONSUMIDOR}

Uma organização de sucesso deve conhecer seus clientes, entender seu cotidiano e as mudanças que ocorrem em suas vidas, podendo assim oferecer produtos e serviços que satisfaçam estes clientes e suas necessidades. 0 estudo do comportamento do consumidor surgiu com este intuito, pois entender como os clientes realizam suas compras pode oferecer oportunidades às empresas (KOTLER, 2000).

Engel, Blackwell e Miniard (2000) acreditam que, para sobreviver, as organizações devem entender o comportamento e motivações dos indivíduos, para que, deste modo, possam desenvolver produtos e serviços que satisfarão as necessidades de seus consumidores.

Uma empresa só torna-se essencial para determinada sociedade quando consegue proporcionar serviços e produtos que atendam às necessidades de seus membros, deixandoos satisfeitos (SHETH, 2001).

De acordo com Chauvel (1999), a satisfação do consumidor é uma avaliação ou julgamento efetuado por cada consumidor depois da efetuação de transações como compra de produtos, solicitação de serviços, experimentação dos produtos e serviços adquiridos. Para Kotler (2000, p. 58), "satisfação consiste na sensação de prazer ou desapontamento resultante da comparação do desempenho (ou resultado) percebido de um produto em relação às expectativas do comprador".

As expectativas que cada consumidor nutre são decisivas para que haja uma boa experiência em relação à aquisição de produtos e serviços, e, consequentemente, para que estes consumidores sejam satisfeitos e repitam a compra (McGOLDRICK, 2002).

Lee (2009) explica que, quando a empresa atende às expectativas dos consumidores em relação aos atributos valorizados no momento da compra e posteriormente, aquela tende a desenvolver uma base considerável de clientes satisfeitos, e, posteriormente, de clientes fiéis.

McGoldrick (2002) afirma que, ao identificar os atributos valorizados pelos consumidores e desenvolver um portfólio capaz de atender às expectativas geradas sobre estes atributos, a empresa consegue manter seus clientes satisfeitos.

Porter (1985), ao propor o modelo da cadeia de valor como uma ferramenta para identificar as maneiras pelas quais se pode criar valor para os clientes, lista nove processos ou atividades estrategicamente relevantes nas organizações para promover a satisfação dos consumidores por meio da entrega de valor, os quais são: (1) logística interna; (2) operações; (3) logística externa; (4) marketing e vendas; (5) serviços; (6) infra-estrutura da empresa; (7) gerência de recursos humanos; (8) desenvolvimento de tecnologia; e (9) aquisição.

Quando a empresa não consegue atender às expectativas dos clientes, aquela passa a ter muitos clientes insatisfeitos, que possivelmente deixarão de comprar e procurarão empresas concorrentes. No entanto, quando os clientes estão muito satisfeitos, dificilmente irão 
procurar as empresas concorrentes, o que ressalta a importância de entender e exceder as expectativas dos consumidores (KOTLER, 2000).

De acordo com Keaveney e Hunt (1992), quando um cliente encontra uma loja, logo o mesmo a compara com exemplos anteriores da mesma categoria de loja, e então analisa o quão diferente ou similar é esta loja em relação ao modelo mental de uma loja nesta categoria.

No entanto, quando a nova loja é muito diferente em relação ao modelo mental do cliente para a categoria de lojas correspondente, este cliente fica marcado por aquelas características distintas, e então, ou modifica seu modelo mental, ou grava aquela loja como uma exceção, boa ou ruim.

Sendo assim, segundo o modelo acima, os clientes formam uma base de expectativas e, quando são surpreendidos de maneira positiva, aquelas expectativas tendem a aumentar, o que mostra a importância de buscar constantemente entender o ponto de vista dos clientes, tanto em relação aos serviços esperados, quanto em relação aos serviços atualmente prestados.

\section{MÉTODO DE PESQUISA}

0 método de pesquisa adotado neste trabalho foi o método quantitativo de caráter exploratório. Segundo Gil (2001) e Cooper e Schindler (2003), a pesquisa exploratória deve ser utilizada em casos nos quais é necessário definir com maior precisão o problema pesquisado, identificar cursos relevantes de ação ou obter dados adicionais antes de poder desenvolver uma abordagem acerca de determinado assunto.

De acordo com Malhotra (2006), deve-se ressaltar que a pesquisa quantitativa é uma metodologia de pesquisa que procura quantificar os dados por meio da aplicação de alguma forma de análise estatística.

Seguindo esta linha de pesquisa, foram elaborados e aplicados questionários utilizando-se perguntas estruturadas, sendo que este tipo de pergunta pré-especifica o conjunto de respostas alternativas e o formato da resposta (MALHOTRA, 2006).

O questionário desenvolvido pelos autores deste estudo utilizou-se do método de escala de Likert, sendo que esta escala é amplamente utilizada em pesquisas e exige que os entrevistados indiquem um grau de concordância ou discordância em relação a cada uma dentre uma série de afirmações sobre o objeto de estudo. Segundo Malhotra (2006), a escala de Likert possui várias vantagens, dentre elas a facilidade de construção e posterior aplicação, além de que os entrevistados entendem rapidamente como utilizá-la, tornando-a adequada para entrevistas postais, telefônicas ou pessoais.

A elaboração do questionário baseou-se no modelo servqual ampliado pelas questões de imagem e marca, que busca medir a satisfação dos consumidores em relação a uma série de atributos. Deve-se ressaltar que o modelo foi adaptado ao contexto das franquias de ensino, partindo-se da experiência dos pesquisadores neste mercado.

As questões de pesquisa, divididas pelas variáveis do modelo servqual ampliado, estão resumidas no quadro 1. 
Foram aplicados neste estudo 177 questionários em quatro diferentes unidades franqueadas das Escolas A na cidade de Ribeirão Preto, sendo que Escolas A é uma rede de franquias que atua no segmento de ensino de línguas estrangeiras, com presença em diversos países.

Deve-se ressaltar que, na coleta de dados, foi utilizado o método de amostragem por conveniência, o que, se por um lado facilita a coleta de dados, por outro, torna-se uma limitação a ser observada caso haja intenção dos autores em generalizar os resultados obtidos (COOPER; SCHINDLER, 2003; GIL, 2001).

Para a aplicação das ferramentas estatísticas na análise dos dados coletados foi utilizado o programa SPSS for Windows 13.0, e as ferramentas utilizadas foram a análise de regressão e estatísticas descritivas, como a média e o desvio padrão.

\section{Quadro 1: Questões de pesquisa por variáveis}

\begin{tabular}{|c|c|}
\hline Tangíveis & $\begin{array}{l}\text { - As instalações físicas (salas de aula, banheiros, recepção, etc) me agradam } \\
\text { - } \quad \text { Sinto-me confortável na sala de aula } \\
\text { - } \quad \text { Considero apropriados os recursos multimídia que a escola disponibiliza } \\
\text { - Os equipamentos que a escola possui estão em boas condições de uso } \\
\text { - Os funcionários estão sempre vestidos de forma adequada } \\
\text { - O material didático é bem estruturado } \\
\text { - A escola possui uma marca forte }\end{array}$ \\
\hline Confiabilidade & 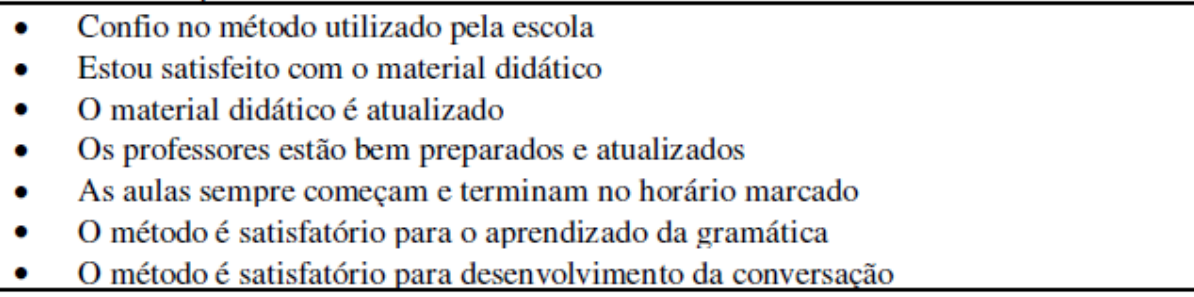 \\
\hline Receptividade & $\begin{array}{ll}\text { - } & \text { Sou rapidamente atendido em minhas solicitações } \\
\text { - } & \text { Os professores estão sempre prontos para ajudar e a tirar duvidas } \\
\text { - } & \text { Os funcionários da recepção estão sempre prontos ajudar } \\
\text { - } & \text { A coordenação se preocupa com meu aprendizado } \\
\text { - } & \text { Sempre que preciso meus problemas são resolvidos } \\
\end{array}$ \\
\hline Segurança & $\begin{array}{l}\text { - O professor gosta de dar aulas } \\
\text { - Os professores sempre me trataram com respeito } \\
\text { - O professor demonstra domínio da matéria } \\
\text { - } \quad \text { Sou atendido cordialmente pelos funcionários } \\
\text { - Professores possuem conhecimento suficiente para responder as dúvidas dos alunos. }\end{array}$ \\
\hline Empatia & $\begin{array}{l}\text { - } \quad \text { Minha opinião é sempre levada em conta } \\
\text { - A escola oferece atenção individual aos alunos. } \\
\text { - Os funcionários demonstram interesse em servir aos alunos. } \\
\text { - } \quad \text { A escola entende as minhas necessidades }\end{array}$ \\
\hline
\end{tabular}

Fonte: Elaborado pelos autores, 2009

\section{APRESENTAÇÃO E DISCUSSÃO DOS RESULTADOS}

Primeiramente, são apresentadas as estatísticas descritivas para cada uma das variáveis de pesquisa na tabela 1 .

Mas antes, deve-se destacar que foram analisados os índices de Skenes para cada variável, que medem o desvio da distribuição em relação à curva normal, sendo que um índice próximo ou maior que um (positivo ou negativo) é considerado excelente, e todas as variáveis apresentaram este índice em valores aceitáveis. 
A última coluna da tabela, que representa a pontuação total de cada uma das variáveis estudadas (a pontuação total máxima poderia alcançar 885 pontos, já que foram entrevistados 177 alunos, que utilizaram para responder uma escala que variou de 1 a 5 sendo 1 muito insatisfeito e 5 muito satisfeito), mostra quais foram os itens mais bem avaliados pelos alunos e quais os itens que devem ser melhorados pela franquia estudada.

Como destaques positivos das escolas franqueadas em estudo, que colaboram para a satisfação dos alunos, deve-se citar a resolução de problemas (Q27), o método adequado para aprimoramento de conversação (Q19) e de gramática (Q14), o rigor com que os horários são cumpridos (Q6), o conforto das salas de aula (Q24), a cordialidade dos funcionários (Q11), a confiança em relação ao método de ensino adotado (Q4) e o fato de que os alunos possuem voz ativa na escola (Q29).

Já como pontos a serem melhorados, do ponto de vista dos alunos, pode-se citar o entendimento das necessidades dos alunos por parte da escola (17), a rapidez com que as solicitações são atendidas (Q21), a atualização do material didático (Q2), o fato de que a coordenação da escola preocupa-se com o aprendizado dos alunos (Q16) e as instalações físicas de modo geral (Q1), que foi o item que obteve pior avaliação.

Deve-se ressaltar que, apesar da questão 30 (de modo geral, minha satisfação com o curso é muito grande) ter obtido uma nota razoavelmente elevada (791) em relação ao máximo possível (885), ainda assim a mesma teve uma das notas mais baixas do questionário, o que indica que os alunos não estão tão satisfeitos.

Também deve ser chamada a atenção para o fato de que as instalações físicas, que podem estar sendo ignoradas pelos franqueados e franqueadores, mostrou-se uma questão relevante, já que, pela pontuação dos alunos, este seria o item que atualmente traz menos satisfação.

Na segunda etapa da pesquisa, foi utilizado o método de regressão, conforme o quadro 2, para definir as variáveis que melhor explicam a satisfação dos alunos.

E, dentre os sete modelos obtidos com a regressão, foi selecionado o modelo 6, por contar com uma quantidade maior de variáveis, e por apresentar o coeficiente R2 ajustado igual a 0,605 (o maior coeficiente dentre todos os modelos, com exceção do modelo 7), o que indica que o modelo explica grande parte da satisfação dos alunos com a escola estudada. 0 modelo 7 não foi selecionado, pois, apesar de conter mais variáveis que o modelo 6 , continha uma variável negativa, o que complicaria excessivamente o modelo. Sendo assim, a equação de regressão obtida na pesquisa foi:

Satisfação da escola $=0,699+0,226^{*} \mathrm{Q} 17+0,205^{*} \mathrm{Q} 25+0,111^{*} \mathrm{Q} 29+0,088^{*} \mathrm{Q} 1+0,1 * \mathrm{Q} 19+$ $0,137^{*} \mathrm{Q} 27$. Sendo:

- $\mathrm{Q} 17$ = A escola entende minhas necessidades.

- $\quad$ Q25 = Estou satisfeito com o material didático.

- $\quad$ Q29 = Minha opinião é sempre levada em conta.

- $\mathrm{Q} 1=$ As instalações físicas me agradam.

- $\mathrm{Q} 19$ = 0 método é satisfatório para desenvolvimento da conversação. 
- $\quad$ Q27 = Sempre que preciso meus problemas são solucionados.

Com este modelo, pode-se auferir que, apesar de haver muitas questões consideradas importantes para os estudantes, aspectos como a qualidade do material didático, a eficácia do método adotado e as instalações físicas são extremamente relevantes para garantir a satisfação dos alunos.

Deve-se ressaltar que estas três variáveis não dependem exclusivamente das escolas franqueadas, já que a rede possui material didático, layout das escolas e método de ensino padronizados.

Isso mostra a importância da comunicação entre franqueados e franqueadores, para que os gestores que acompanham o cotidiano dos alunos nas escolas franqueadas possam levar sugestões à rede franqueadora, de modo a adaptar e melhorar os padrões pré-estabelecidos de acordo com a realidade e expectativas dos alunos.

Tabela 1: Estatísticas descritivas 


\begin{tabular}{|c|c|c|c|c|c|c|c|c|c|c|}
\hline & Mean & Median & Mode & $\begin{array}{l}\text { Std. } \\
\text { Deviation }\end{array}$ & Variance & Skewness & $\begin{array}{l}\text { Std. Error } \\
\text { of } \\
\text { Skewness }\end{array}$ & Kurtosis & $\begin{array}{l}\text { Std. Error } \\
\text { of } \\
\text { Kurtosis }\end{array}$ & Sum \\
\hline Q1 & 27,910 & 20,000 & 1,00 & 195,876 & 3,837 & ,875 & 183 &,- 225 & ,363 & 494,00 \\
\hline Q2 & 42,881 & 50,000 & 5,00 & ,88647 & ,786 & $-1,145$ & , 183 & ,745 & ,363 & 759,00 \\
\hline Q3 & 46,723 & 50,000 & 5,00 & ,67838 & ,460 & $-2,580$ & 183 & 7,776 & ,363 & 827,00 \\
\hline Q4 & 48,475 & 50,000 & 5,00 & ,41888 & , 175 & $-3,303$ & , 183 & 13,908 & ,363 & 858,00 \\
\hline Q5 & 46,441 & 50,000 & 5,00 & ,65094 & ,424 & $-2,362$ & 183 & 7,427 & ,363 & 822,00 \\
\hline Q6 & 49,153 & 50,000 & 5,00 & ,39693 & 158 & $-6,786$ & 183 & 57,287 & ,363 & 870,00 \\
\hline Q7 & 46,441 & 50,000 & 5,00 & ,74839 &, 560 & $-2,848$ & 183 & 9,531 & ,363 & 822,00 \\
\hline Q8 & 47,232 & 50,000 & 5,00 & ,59082 & ,349 & $-2,681$ & 183 & 9,645 & ,363 & 836,00 \\
\hline Q9 & 47,175 & 50,000 & 5,00 & ,58327 & ,340 & $-2,296$ & 183 & 5,616 & ,363 & 835,00 \\
\hline Q10 & 46,780 & 50,000 & 5,00 & ,59660 & ,356 & $-2,018$ & 183 & 4,376 & ,363 & 828,00 \\
\hline Q11 & 48,701 & 50,000 & 5,00 & ,43960 & , 193 & $-5,098$ & , 183 & 35,728 & ,363 & 862,00 \\
\hline Q12 & 47,006 & 50,000 & 5,00 & 66200 & ,438 & $-2,792$ & 183 & 9,108 & ,363 & 832,00 \\
\hline Q13 & 45,028 & 50,000 & 5,00 & ,70810 &, 501 & $-1,370$ & 183 & 1,485 & ,363 & 797,00 \\
\hline Q14 & 49,040 & 50,000 & 5,00 & ,37965 & ,144 & $-4,782$ & 183 & 26,404 & ,363 & 868,00 \\
\hline Q15 & 46,497 & 50,000 & 5,00 & ,63193 & ,399 & $-2,426$ & 183 & 8,315 & ,363 & 823,00 \\
\hline Q16 & 41,921 & 40,000 & 5,00 & ,93986 & ,883 & $-1,058$ & 183 & ,601 & ,363 & 742,00 \\
\hline Q17 & 43,220 & 50,000 & 5,00 & ,82104 & ,674 & $-1,158$ & 183 & 1,152 & ,363 & 765,00 \\
\hline Q18 & 44,633 & 50,000 & 5,00 & ,72304 & ,523 & $-1,148$ & ,183 & ,545 & ,363 & 790,00 \\
\hline Q19 & 49,266 & 50,000 & 5,00 & ,38469 & , 148 & $-7,389$ & 183 & 65,846 & ,363 & 872,00 \\
\hline Q20 & 45,876 & 50,000 & 5,00 & ,74959 & ,562 & $-2,104$ & 183 & 4,704 & ,363 & 812,00 \\
\hline Q21 & 43,164 & 50,000 & 5,00 & ,92406 & ,854 & $-1,458$ & 183 & 1,926 & ,363 & 764,00 \\
\hline Q22 & 46,045 & 50,000 & 5,00 & ,64101 & ,411 & $-2,035$ & 183 & 6,151 & ,363 & 815,00 \\
\hline Q23 & 45,989 & 50,000 & 5,00 & ,72504 & ,526 & $-2,205$ & 183 & 6,063 & ,363 & 814,00 \\
\hline Q24 & 49,096 & 50,000 & 5,00 & ,38842 & ,151 & $-6,734$ & 183 & 59,412 & ,363 & 869,00 \\
\hline Q25 & 46,836 & 50,000 & 5,00 & ,66692 & ,445 & $-3,256$ & 183 & 14,138 & ,363 & 829,00 \\
\hline Q26 & 46,780 & 50,000 & 5,00 & ,63355 & ,401 & $-2,460$ & ,183 & 7,856 & ,363 & 828,00 \\
\hline Q27 & 49,379 & 50,000 & 5,00 & ,37170 & ,138 & $-8,104$ & ,183 & 76,539 & ,363 & 874,00 \\
\hline Q28 & 47,175 & 50,000 & 5,00 & ,57345 & ,329 & $-2,650$ & 183 & 10,262 & ,363 & 835,00 \\
\hline Q29 & 47,853 & 50,000 & 5,00 & ,57328 & ,329 & $-3,996$ & 183 & 20,959 & ,363 & 847,00 \\
\hline \multirow[t]{2}{*}{ Q30 } & 44,689 & 50,000 & 5,00 & ,81212 & ,660 & $-1,701$ & 183 & 3,147 & ,363 & 791,00 \\
\hline & 46,497 & 50,000 & 5,00 &, 57546 & ,331 & $-1,603$ & , 183 & 2,522 & ,363 & 823,00 \\
\hline
\end{tabular}

Fonte: Output SPSS, 2009

Também se deve destacar o fato de que os alunos esperam ter suas reclamações e problemas resolvidos pela escola, e esperam ser ouvidos, de forma que suas opiniões e pontos de vista sempre sejam levados em consideração. E, ao contrário dos pontos anteriores, estes dois itens dependem mais da administração das escolas franqueadas do que da rede franqueadora.

Com isso, pode-se perceber a importância de que haja sempre um trabalho conjunto entre franqueados e franqueadores; os primeiros, levando informações para a rede franqueadora e atendendo às demandas de seus alunos, e os segundos, buscando ouvir os franqueados e adaptando, na medida do possível, as práticas e padrões desenvolvidos, de modo a conseguir maior satisfação dos clientes finais (os alunos).

Resumindo, os alunos tornam-se satisfeitos na medida em que se sentem respeitados pela escola enquanto aprendizes, já que os mesmos esperam que a escola de idiomas escolhida seja capaz de fornecer condições (incluindo material didático, instalações físicas e método de 
ensino) que favoreçam seu aprendizado. E, além disso, estes alunos esperam que os gestores destas escolas mostrem-se preocupados com seu aprendizado e com suas demandas, já que a capacidade de a instituição de ensino resolver quaisquer problemas ou dificuldades apresentadas pelos alunos mostrou-se essencial para que estes se mantenham satisfeitos com o curso e a escola escolhida.

E, para que isto ocorra, a franquia não deve considerar os alunos apenas como clientes, e sim como indivíduos com necessidades de aprendizado e aprimoramento constantes. Antes de clientes, os alunos devem ser encarados como alunos e agentes ativos, que desejam participar de seu próprio processo de aprendizagem, e que esperam ser constantemente consultados e ouvidos pelos gestores da escola de idiomas na qual o curso está sendo realizado.

Finalizando, deve-se ressaltar a importância do desenvolvimento de um processo de comunicação que envolva três eixos: alunos - gestores das escolas franqueadas - rede franqueadora. Deste modo, a rede franqueadora, além de estar mais próxima dos alunos, facilitando a implementação de mudanças positivas nos procedimentos e padrões adotados para as franquias, ainda estará mais próxima dos franqueados, o que poderá facilitar a troca de informações relevantes, que possam auxiliar tanto a rede franqueadora quanto as escolas no desenvolvimento de programas que poderão gerar maior satisfação por parte dos alunos.

Quadro 2: Análise de regressão 


\begin{tabular}{|c|c|c|c|c|c|c|c|c|}
\hline \multirow[b]{2}{*}{ Model } & & \multicolumn{2}{|c|}{$\begin{array}{l}\text { Unstandardized } \\
\text { Coefficients }\end{array}$} & \multirow{2}{*}{$\begin{array}{l}\text { Standardiz } \\
\text { ed } \\
\text { Coefficient } \\
\text { s } \\
\text { Beta } \\
\end{array}$} & \multirow[t]{2}{*}{$\mathrm{t}$} & \multirow[t]{2}{*}{ Sig. } & \multicolumn{2}{|c|}{ Collinearity Statistics } \\
\hline & & $\mathrm{B}$ & Std. Error & & & & Tolerance & VIF \\
\hline 1 & $\begin{array}{l}\text { (Constant) } \\
\text { Q17 }\end{array}$ & $\begin{array}{l}2,286 \\
0,53\end{array}$ & $\begin{array}{l}0,203 \\
0,045\end{array}$ & 0,665 & $\begin{array}{l}11,259 \\
11,79\end{array}$ & $\begin{array}{l}0 \\
0\end{array}$ & 0,665 & 0,665 \\
\hline 2 & $\begin{array}{l}\text { (Constant) } \\
\text { Q17 } \\
\text { Q25 }\end{array}$ & $\begin{array}{l}1,388 \\
0,358 \\
0,356\end{array}$ & $\mid \begin{array}{l}0,23 \\
0,049 \\
0,055\end{array}$ & $\begin{array}{l}0,449 \\
0,392\end{array}$ & $\begin{array}{l}6,026 \\
7,374 \\
6,43\end{array}$ & $\begin{array}{l}0 \\
0 \\
0\end{array}$ & $\begin{array}{l}0,488 \\
0,438\end{array}$ & $\begin{array}{l}0,375 \\
0,327\end{array}$ \\
\hline 3 & $\begin{array}{l}\text { (Constant) } \\
\text { Q17 } \\
\text { Q25 } \\
\text { Q29 }\end{array}$ & $\begin{array}{l}1,291 \\
0,302 \\
0,297 \\
0,139 \\
\end{array}$ & $\begin{array}{l}0,227 \\
0,05 \\
0,057 \\
0,044\end{array}$ & $\begin{array}{l}0,38 \\
0,327 \\
0,196 \\
\end{array}$ & $\begin{array}{l}5,691 \\
5,991 \\
5,196 \\
3,141 \\
\end{array}$ & $\begin{array}{l}0 \\
0 \\
0 \\
0,002\end{array}$ & $\begin{array}{l}0,415 \\
0,367 \\
0,232 \\
\end{array}$ & $\begin{array}{l}0,297 \\
0,258 \\
0,156 \\
\end{array}$ \\
\hline 4 & $\begin{array}{l}\text { (Constant) } \\
\text { Q17 } \\
\text { Q25 } \\
\text { Q29 } \\
\text { Q1 }\end{array}$ & $\begin{array}{l}1,08 \\
0,289 \\
0,277 \\
0,127 \\
0,097 \\
\end{array}$ & $\begin{array}{l}0,233 \\
0,05 \\
0,056 \\
0,043 \\
0,033\end{array}$ & $\begin{array}{l}0,363 \\
0,305 \\
0,18 \\
0,149\end{array}$ & $\begin{array}{l}4,626 \\
5,827 \\
4,908 \\
2,937 \\
2,921 \\
\end{array}$ & $\begin{array}{l}0 \\
0 \\
0 \\
0,004 \\
0,004\end{array}$ & $\begin{array}{l}0,406 \\
0,35 \\
0,219 \\
0,217 \\
\end{array}$ & $\begin{array}{l}0,283 \\
0,238 \\
0,143 \\
0,142\end{array}$ \\
\hline 5 & $\begin{array}{l}\text { (Constant) } \\
\text { Q17 } \\
\text { Q25 } \\
\text { Q29 } \\
\text { Q1 } \\
\text { Q19 }\end{array}$ & $\begin{array}{l}0,937 \\
0,257 \\
0,239 \\
0,127 \\
0,094 \\
0,104 \\
\end{array}$ & $\begin{array}{l}0,238 \\
0,051 \\
0,058 \\
0,043 \\
0,033 \\
0,044 \\
\end{array}$ & $\begin{array}{l}0,323 \\
0,263 \\
0,179 \\
0,145 \\
0,136 \\
\end{array}$ & \begin{tabular}{|l}
3,939 \\
5,05 \\
4,123 \\
2,958 \\
2,88 \\
2,374 \\
\end{tabular} & $\begin{array}{l}0 \\
0 \\
0 \\
0,004 \\
0,004 \\
0,019 \\
\end{array}$ & $\begin{array}{l}0,36 \\
0,301 \\
0,221 \\
0,215 \\
0,179 \\
\end{array}$ & $\begin{array}{l}0,242 \\
0,198 \\
0,142 \\
0,138 \\
0,114 \\
\end{array}$ \\
\hline 6 & $\begin{array}{l}\text { (Constant) } \\
\text { Q17 } \\
\text { Q25 } \\
\text { Q29 } \\
\text { Q1 } \\
\text { Q19 } \\
\text { Q27 } \\
\end{array}$ & $\begin{array}{l}0,699 \\
0,226 \\
0,205 \\
0,111 \\
0,088 \\
0,1 \\
0,137 \\
\end{array}$ & $\begin{array}{l}0,259 \\
0,052 \\
0,059 \\
0,043 \\
0,032 \\
0,044 \\
0,062 \\
\end{array}$ & $\begin{array}{l}0,285 \\
0,226 \\
0,157 \\
0,135 \\
0,13 \\
0,137 \\
\end{array}$ & $\begin{array}{l}2,699 \\
4,347 \\
3,469 \\
2,598 \\
2,702 \\
2,291 \\
2,213 \\
\end{array}$ & $\begin{array}{l}0,008 \\
0 \\
0,001 \\
0,01 \\
0,008 \\
0,023 \\
0,028 \\
\end{array}$ & $\begin{array}{l}0,316 \\
0,257 \\
0,195 \\
0,203 \\
0,173 \\
0,167 \\
\end{array}$ & $\begin{array}{l}0,206 \\
0,164 \\
0,123 \\
0,128 \\
0,109 \\
0,105 \\
\end{array}$ \\
\hline 7 & $\begin{array}{l}\text { (Constant) } \\
\text { Q17 } \\
\text { Q25 } \\
\text { Q29 } \\
\text { Q1 } \\
\text { Q19 } \\
\text { Q27 } \\
\text { Q6 }\end{array}$ & $\begin{array}{l}0,881 \\
0,218 \\
0,21 \\
0,131 \\
0,09 \\
0,101 \\
0,173 \\
-0,094 \\
\end{array}$ & $\begin{array}{l}0,267 \\
0,052 \\
0,058 \\
0,043 \\
0,032 \\
0,043 \\
0,063 \\
0,04\end{array}$ & $\begin{array}{l}0,274 \\
0,231 \\
0,185 \\
0,139 \\
0,132 \\
0,172 \\
-0,123 \\
\end{array}$ & $\begin{array}{l}3,301 \\
4,24 \\
3,587 \\
3,034 \\
2,818 \\
2,35 \\
2,745 \\
-2,364 \\
\end{array}$ & $\begin{array}{l}0,001 \\
0 \\
0 \\
0,003 \\
0,005 \\
0,02 \\
0,007 \\
0,019\end{array}$ & $\begin{array}{l}0,31 \\
0,266 \\
0,227 \\
0,212 \\
0,178 \\
0,207 \\
-0,179 \\
\end{array}$ & $\begin{array}{l}0,198 \\
0,168 \\
0,142 \\
0,132 \\
0,11 \\
0,128 \\
-0,111 \\
\end{array}$ \\
\hline
\end{tabular}

Fonte: Output SPSS, 2009.

\section{CONSIDERAÇÕES FINAIS}

O presente estudo teve como objetivo avaliar a satisfação de clientes de uma franquia de ensino de línguas por meio do modelo servqual ampliado por questões de imagem e marca.

Foram aplicados questionários em uma amostra de 177 alunos de quatro diferentes escolas, todas pertencentes a uma mesma rede de franquias. Deve-se destacar que a rede de franquias estudada possui uma grande tradição e está consolidada há cerca de cinquenta anos no mercado brasileiro, e, além disso, as escolas estudadas já existem há mais de 30 anos em Ribeirão Preto, o que ajuda na formação de uma imagem positiva na cidade.

Conforme se pode observar nos resultados obtidos, em geral os alunos estão muito satisfeitos com o curso de línguas fornecido pela rede estudada, mas existem alguns itens que se colocaram como fundamentais para a total satisfação destes consumidores e que não estavam 
sendo atendidos de maneira adequada. Questões de caráter tangível, principalmente relacionadas às instalações física da escola e manutenção de equipamentos mostraram-se pontos sensíveis segundo a visão dos consumidores.

Já dentre os fatores que se destacaram positivamente para a satisfação dos alunos estão aqueles ligados à confiabilidade e receptividade. Também devem ser destacados os aspectos relacionados à empatia dos funcionários, que se mostraram de fundamental importância na composição da satisfação dos alunos.

Outra consideração a ser feita é que o aluno se preocupa muito com questões que dizem respeito a como ele é respeitado pela escola e acerca dos esforços desta para entender suas necessidades, além de que o aluno espera ter sua opinião sempre levada em consideração e sentir que será atendido quando necessitar. Tais resultados demonstram a importância dos recursos humanos dentro de uma escola, sendo que questões como recrutamento e treinamento de pessoal passam a ser considerados como de extrema importância para o sucesso da empresa e a satisfação dos clientes.

Também se deve citar que, segundo o modelo desenvolvido para avaliar a satisfação dos alunos, tanto os franqueados quanto os franqueadores devem trabalhar de maneira conjunta, já que existem questões como condições das instalações físicas e prontidão para resolver problemas que dependem dos franqueados, assim como questões como material didático e método de ensino que dependem dos franqueadores.

Finalmente, deve ser ressaltada a importância de haver uma comunicação constante entre franqueados e franqueadores, já que, como os franqueados estão diretamente ligados aos clientes e entendem de forma mais clara suas demandas, aqueles devem levar informações relevantes aos franqueadores, para que os métodos e demais padrões definidos pela rede de franquias possam estar sempre atualizados e em consonância com as necessidades dos clientes.

Como sugestão para estudos futuros, os autores deste trabalho sugerem que as questões levantadas nesta pesquisa sejam utilizadas em outras pesquisas com escolas que fazem parte de redes de franquias, para validar o modelo servqual adaptado pelos autores.

E como limitação deste estudo, pode-se citar o tamanho da amostra, que poderia ser ampliado em estudos futuros, e o fato de que foi utilizada uma amostragem por conveniência.

Além disso, como foram estudados apenas alunos de escolas localizadas em Ribeirão Preto, os resultados podem sofrer alterações significativas, caso esta mesma pesquisa seja conduzida em outras regiões do país. Sendo assim, outras pesquisas poderiam ser conduzidas, de modo a verificar se o modelo pode ser utilizado para avaliar a satisfação de alunos de escolas que fazem parte de outras redes de franquias de ensino, em diversas regiões do país.

\section{REFERÊNCIAS BIBLIOGRÁFICAS}

ASSOCIAÇÃO BRASILEIRA DE FRANCHISIG. Disponível em: www.abf.com.br Acesso em: 3 dez. 2009.

CHAUVEL, Maria Agnes. A satisfação do consumidor no pensamento de marketing: revisão e literatura. In: Congresso ANPAD, 22, 1999, Foz do Iguaçu. Anais ANPAD/ENANPAD. São Paulo, 1999, 1CD. 
COOPER, D. R.;SCHINDLER, P. S. Métodos de pesquisa em administração. 7a ed. Porto Alegre: Editora Bookman, 2003.

DAHAB, Sônia, et al. Entendendo franchising: uma alternativa eficaz para o pequeno e médio empreendedor. Salvador: Casa da Qualidade, 1996.

ENGEL, James F.; BLACKWELL, Roger D.; MINIARD, Paul W. Comportamento do consumidor. Rio de Janeiro: LCT, 2000.

FOSTER, Dennis L. 0 livro completo do franchising. Rio de Janeiro: Infobook, 1995.

GIL, Antônio C. Como elaborar projetos de pesquisa. 4. ed. São Paulo: Atlas, 2001.

LEVY, Michael; WEITZ, Barton A. Administração de varejo. São Paulo: Atlas, 2000.

KEAVENEY, Susan M.; HUNT, Kenneth A. Conceptualization and operationalization of retail store image: a case of rival middle-level theories. Journal of the Academy of Marketing Science, v. 20, n. 2, p. 165-175, 1992.

KOTLER, P. Administração de Marketing. Editora Prentice Hall, São Paulo, 2000.

LEE, W. T. The impact of store attributes on consumer shopping behaviour: a study of grocery stores. 2009. Dissertation (Master of Business Administration). Faculty of Business and Accountancy, University of Malaya, Kuala Lumpur, 2009.

MALHOTRA, N. W. Pesquisa de marketing: uma orientação científica. 4. ed. Porto Alegre: Bookman, 2006.

MAURO, P. C. Guia do franqueador: como crescer através do franchising. 3. ed. rev. amp. São Paulo: Nobel, 1999.

McGOLDRICK, Peter J. Retail Marketing. Londres: McGraw-Hill, 2002.

MORGENSTEIN, M.; STRONGIN, H. Modern retailing. 3rd ed. USA: Prentice Hall, 1992.

PARENTE, Juracy. Varejo no Brasil: gestão e estratégia. São Paulo: Atlas, 2000.

PORTER, Michael E. Competitive advantage: creating and sustaining superior performance. Nova York: Free Press, 1985.

SHETH, J. N.; MITTAL, B.; NEWMAN, B. Comportamento do cliente. São Paulo: Atlas,2001. 